\title{
Return to sports activity after opening wedge high tibial osteotomy in patients aged 70 years and older
}

\author{
Akio Otoshi, Ken Kumagai* (i), Shunsuke Yamada, Shuntaro Nejima, Takahiro Fujisawa, Kazuma Miyatake and
} Yutaka Inaba

\begin{abstract}
Background: The purpose of this study was to evaluate return to sports (RTS) after opening wedge high tibial osteotomy (OWHTO) in elderly patients and associated factors affecting RTS.

Methods: Seventy-four patients (mean age 68 years) who underwent OWHTO were enrolled. Clinical outcomes were evaluated using the Knee Society Score (KSS). Patients were asked regarding types of sports activities and their levels of participation within preoperative 1 year and postoperative 1 year. Levels of participation in sports and recreational activities were examined using the Tegner activity scale. The outcomes were compared between two age groups ( $\geq 70$ years vs. $<70$ years).

Results: Of the 74 patients overall, 59 participated in at least one sport preoperatively, and 55 returned to sports postoperatively (RTS 93\%). The KSS knee score and function score were significantly improved after surgery in both age groups $(P<0.05)$, but no significant differences were found between the age groups. The Tegner activity scales for $\geq 70$ years and $<70$ years were $2.9 \pm 1.1$ and $4.0 \pm 1.9$ preoperatively $(P<0.01)$ and $2.7 \pm 1.2$ and $3.3 \pm 1.4$ postoperatively $(P=0.16)$, respectively. RTS was reported by 24 of $25(96.0 \%)$ in the age $<70$ years group and 31 of 34 (91.2\%) in the age $\geq 70$ years group. Majority of age $\geq 70$ years participated in low-impact sports preoperatively and returned to the same impact level postoperatively.
\end{abstract}

Conclusions: The rate of RTS after OWHTO was high in patients aged 70 years and older with low-impact level. OWHTO is a preferred surgical option for elderly patients who desire RTS.

Keywords: Opening wedge high tibial osteotomy, Return to sports, Elderly patients

\section{Introduction}

Osteoarthritis (OA) of the knee is a common disease in the aged population and the leading cause of restriction of activities of daily living (ADL). Since most countries have rising life expectancy and an aging population, extension of healthy life expectancy is a critical issue, and

*Correspondence: kumagai@yokohama-cu.ac.jp

Department of Orthopaedic Surgery, Graduate School of Medicine, Yokohama City University, 3-9 Fukuura, Kanazawa-ku, Yokohama 236-0004, Japan an improvement of quality of life, including enjoyment of sports activities, is often required.

High tibial osteotomy (HTO) is an established treatment option for OA of the knee. The procedure is performed to correct lower limb alignment and reduce mechanical force on the affected compartment. Proper overcorrection provides pain relief and subsequent improvement of knee function $[1,2]$. The opening wedge HTO (OWHTO) has recently become commonly used, and good mid-term to long-term clinical outcomes have been demonstrated in patients over 70 years of age [3]. original author(s) and the source, provide a link to the Creative Commons licence, and indicate if changes were made. The images or other third party material in this article are included in the article's Creative Commons licence, unless indicated otherwise in a credit line to the material. If material is not included in the article's Creative Commons licence and your intended use is not permitted by statutory regulation or exceeds the permitted use, you will need to obtain permission directly from the copyright holder. To view a copy of this licence, visit http://creativecommons.org/licenses/by/4.0/. The Creative Commons Public Domain Dedication waiver (http://creativeco mmons.org/publicdomain/zero/1.0/) applies to the data made available in this article, unless otherwise stated in a credit line to the data. 
The advantage of HTO compared to knee replacement surgeries is that it is a joint-preserving procedure that is good for maintaining physical and sports activities [4]. Several studies reported a high rate of return to sports (RTS) activity after OWHTO [5-7]. However, most of the reports involved younger patients, and the rate of RTS in elderly patients is unknown. Furthermore, factors related to RTS after HTO have not been well-elucidated.

The purpose of this study was to evaluate RTS after OWHTO in elderly patients more than 70 years of age and identify factors related to RTS. It was hypothesized

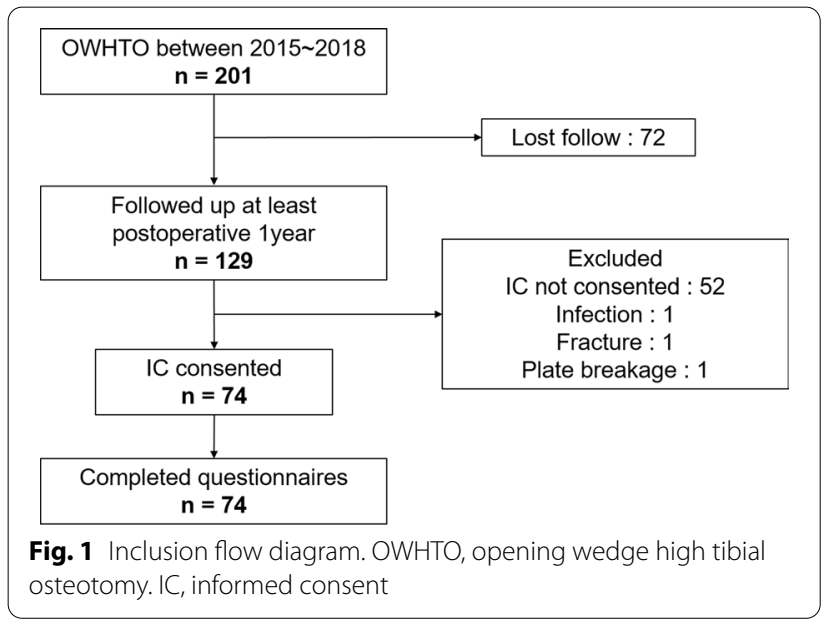

that the rate of RTS after OWHTO is high in patients aged 70 years and older.

\section{Materials and methods \\ Patients}

A total of 201 patients underwent OWHTO between 2015 and 2018. All patients underwent magnetic resonance imaging examination preoperatively to assess cartilage, meniscus, ligament, and subchondral bone in the affected knee joint. Inclusion criteria were painful osteoarthritis or osteonecrosis localized to the medial compartment of the knee. Exclusion criteria were patients with severe varus deformity (anatomical varus alignment $>5^{\circ}$ ), flexion contracture $>15^{\circ}$, or a history of inflammatory arthritis, joint infection, or immunosuppressive therapy. Following the surgery, 129 patients were followed-up appropriately for at least one year. Of these patients, 74 completed questionnaires (Fig. 1). The patients consisted of 55 female and 19 male patients, with mean age of $68.1 \pm 8.1$ years (median age of 70 , range, 49-83 years). The mean follow-up period was $32.9 \pm 12.9$ months (range, $12-59$ months). To evaluate the effect of age, outcomes were compared between two age groups ( $\geq 70$ years vs. $<70$ years). Demographic data are shown in Table 1 . This study was approved by the institutional review board of Yokohama City University (\#B190900037). Written, informed consent was obtained from all participants.

Table 1 Patients' baseline characteristics

\begin{tabular}{|c|c|c|c|c|c|}
\hline & & Overall & $<70$ years & $\geq 70$ years & ${ }^{*} P$ value \\
\hline Age, years & & $68.1 \pm 8.1$ & $61.3 \pm 5.3$ & $74.8 \pm 3.7$ & \\
\hline Number of patients & & 74 & 36 & 38 & \\
\hline Male & & 19 & 15 & 4 & \\
\hline Female & & 55 & 21 & 34 & $<0.01$ \\
\hline Body mass index, $\mathrm{kg} / \mathrm{m}^{2}$ & & $25.5 \pm 4.6$ & $26.1 \pm 5.5$ & $25.0 \pm 3.4$ & 0.34 \\
\hline Follow- up period, months & & $32.9 \pm 12.9$ & $33.8 \pm 13.7$ & $31.2 \pm 12.6$ & 0.18 \\
\hline $\mathrm{OA}, \mathrm{n}$ & & 49 & 27 & 22 & \\
\hline \multirow[t]{3}{*}{${ }^{\dagger}$ Grade } & 1 & 3 & 1 & 2 & \\
\hline & 2 & 28 & 14 & 14 & \\
\hline & 3 & 18 & 12 & 6 & 0.40 \\
\hline ON, n & & 32 & 14 & 18 & \\
\hline \multirow[t]{4}{*}{ ‡Stage } & 1 & 2 & 2 & 0 & \\
\hline & 2 & 0 & 0 & 0 & \\
\hline & 3 & 4 & 2 & 2 & \\
\hline & 4 & 26 & 10 & 16 & 0.23 \\
\hline
\end{tabular}

\footnotetext{
${ }^{*}<70$ years vs $\geq 70$ years

$O A$ osteoarthritis, $O N$ osteonecrosis

${ }^{\dagger}$ OA grade modified from Ahlbach's classification

${ }^{\ddagger} \mathrm{ON}$ stage classification described by Koshino
} 


\section{Surgical procedure and postoperative management}

HTO was performed using biplanar opening-wedge technique with rigid plate fixation [3]. The amount of angular correction was planned preoperatively aiming to achieve tibiofemoral anatomical valgus of $10^{\circ}$ in a one-leg standing radiograph postoperatively. The osteotomy gap was filled with two wedged blocks of $\beta$-TCP with $60 \%$ porosity (Osferion, Olympus Terumo Biomaterials. Corp., Tokyo, Japan) and fixed with TomoFix (DePuy Synthes, Zuchwil, Switzerland).

Patients started a postoperative rehabilitation program including isometric quadriceps and range-of-motion exercises the day after surgery. A non-weight-bearing regimen was prescribed for 1 week, followed by full weight-bearing exercise. Casts or supportive devices were not applied.

\section{Clinical and radiographic outcomes}

Clinical outcomes were evaluated using the Knee Society Score (KSS), including the knee score and the function score. For radiographic assessment, a long-leg anteroposterior weight-bearing radiograph of the knee was taken 1 year after surgery. Limb alignment was expressed as the femorotibial angle (FTA), defined as the lateral angle between the femoral tibial axes [2], and the percentage of mechanical axis deviation (\%MAD), defined as the ratio of the distance from the medial border of the proximal tibia to the mechanical axis of the lower limb to the width of the proximal tibia [8].

\section{Sports activity questionnaire}

Patients were asked about types of sports activities and levels of participation within preoperative 1 year and postoperative 1 year. Levels of impact in sports activities were categorized into three groups: high-impact sports such as tennis, badminton, and running; intermediateimpact sports such as hill walking/hiking and climbing; and low-impact sports such as walking, gymnastic training, and golf [9]. If patients participated in two or more sports activities, the impact level was classified by the highest one. Levels of participation in sports and recreational activities were examined using the Tegner activity scale [10]. RTS was defined as preoperative and postoperative participation in one or more sports and recreational activities. Patients who took part in no sports preoperatively and started postoperatively were excluded from RTS. RTS levels were classified into the following three groups based on the preoperative and postoperative Tegner activity scales: higher level (Preop.<Postop.); same level (Preop.=Postop.); and lower level (Preop. $>$ Postop.).

\section{Statistical analysis}

Statistical analysis was carried out using SPSS ver. 26.0 (SPSS, Inc., Chicago, IL). The Mann-Whitney U test was used to compare measurements between the two groups. Pearson's Chi-squared tests were used to test for significant differences of categorical data. Univariate analysis and multivariate logistic regression were used to identify factors related to the level of RTS. An adjusted $P$ value $<0.05$ was considered significant. A post hoc power analysis was performed for comparison of two age groups. Consequently, the statistical power was calculated to be $92 \%$ for a sample size of 36 and 38 in each group to detect a significant difference with an $\alpha$ level of 0.05 .

\section{Results}

\section{Clinical and radiographic outcomes}

Clinical and radiographic outcomes are summarized in Table 2. The KSS knee score and function score were significantly improved after surgery overall and in both age groups $(P<0.05)$, but no significant differences were found between the $\geq 70$ years and $<70$ years groups. Standing FTA and \%MAD were significantly changed after surgery in both age groups $(P<0.05)$, but there were no significant differences between the two age groups.

\section{Return to sports}

Types of sports activities are shown in Table 3. The number of low-impact sports increased postoperatively, whereas the number of intermediate-impact and highimpact sports decreased postoperatively. Comparisons of type of sports activities between age groups are summarized in Table 4 . Of the overall 74 patients, 59 participated in at least one sport preoperatively, and 55 returned to sports postoperatively (RTS rate 93\%). The number reporting RTS was 24 of $25(96.0 \%)$ in the age $<70$ years group and 31 of $34(91.2 \%)$ in the age $\geq 70$ years group.

Table 2 Clinical and radiographic outcomes

\begin{tabular}{llclll}
\hline & & Overall & $<\mathbf{7 0}$ years & $\mathbf{2} \mathbf{7 0}$ years & *P value \\
\hline Knee & Preop & $57.3 \pm 13.6$ & $59.0 \pm 13.0$ & $57.2 \pm 11.8$ & 0.38 \\
score & Postop & $83.9 \pm 10.1$ & $87.1 \pm 8.3$ & $82.8 \pm 10.0$ & 0.09 \\
Function & Preop & $65.9 \pm 11.1$ & $66.0 \pm 10.3$ & $66.1 \pm 11.8$ & 0.69 \\
score & Postop & $87.7 \pm 12.2$ & $89.9 \pm 12.2$ & $86.7 \pm 12.5$ & 0.20 \\
sFTA & Preop & $181.1 \pm 2.4$ & $181.2 \pm 1.4$ & $180.9 \pm 2.4$ & 0.50 \\
& Postop & $171.4 \pm 2.8$ & $171.8 \pm 1.9$ & $171.1 \pm 2.9$ & 0.59 \\
\%MAD & Preop & $21.2 \pm 11.7$ & $20.2 \pm 112.0$ & $22.2 \pm 11.4$ & 0.39 \\
& Postop & $64.2 \pm 10.8$ & $66.0 \pm 8.9$ & $62.4 \pm 12.1$ & 0.26 \\
\hline
\end{tabular}

${ }^{*}<70$ years versus $\geq 70$ years

sFTA standing femorotibial angle, MAD mechanical axis deviation

The values are given as mean \pm standard deviation 
Table 3 Types of sports activities

\begin{tabular}{|c|c|c|}
\hline Type of sports & Preoperative & Postoperative \\
\hline \multicolumn{3}{|l|}{ High-impact sports } \\
\hline Badminton & 2 & 0 \\
\hline Running & 2 & 1 \\
\hline Tennis & 4 & 2 \\
\hline Baseball & 1 & 1 \\
\hline Softball & 2 & 2 \\
\hline Marathon & 1 & 0 \\
\hline Volleyball & 2 & 1 \\
\hline Table tennis & 1 & 1 \\
\hline Total & 15 & 8 \\
\hline \multicolumn{3}{|c|}{ Intermediate-impact sports } \\
\hline Hill walking/Hiking & 3 & 0 \\
\hline Climbing & 3 & 3 \\
\hline Skiing & 1 & 0 \\
\hline Total & 7 & 3 \\
\hline \multicolumn{3}{|l|}{ Low-impact sports } \\
\hline Walking & 22 & 27 \\
\hline Gymnastic training & 9 & 8 \\
\hline Swimming & 4 & 6 \\
\hline Exercise/Yoga & 6 & 10 \\
\hline Golf & 8 & 8 \\
\hline Gardening & 2 & 3 \\
\hline Cycling & 3 & 2 \\
\hline Tai Chi & 0 & 1 \\
\hline Sports climbing & 1 & 1 \\
\hline Total & 55 & 66 \\
\hline
\end{tabular}

The values are given as the number of patients

Seven patients who had not been involved in sports activities newly participated in sports activities after surgery. Overall, the rate of low-impact sports was greater and increased postoperatively. In the age $\geq 70$ years group, one patient participated in high-impact sports (Softball) and three patients participated in intermediate-impact sports (Climbing). The majority of sports that participants in the age $\geq 70$ years group were involved were low -impact sports preoperatively and postoperatively.

\section{Comparisons of RTS levels between age groups}

Of the patients reporting RTS, 16 of 24 (66.7\%) in the age $<70$ years group and 24 of $31(77.4 \%)$ in the age $\geq 70$ years group could return to the same or higher level (Table 5). The Tegner activity scales decreased postoperatively in both age group; however, these were not significantly different. The preoperative Tegner activity scale was significantly lower in the age $\geq 70$ years group than in the age $<70$ years group $(P<0.01)$, but no significant difference was found in the postoperative score between the age groups.

\section{Comparisons of outcomes between osteoarthritis and osteonecrosis}

The outcomes were compared between osteoarthritis and osteonecrosis (Table 6). No significant differences were found in clinical outcomes, radiographic outcomes, RTS, and sports impact level between two disease entities.

\section{Factors related to the RTS level}

To assess factors related to the RTS level, several variables were compared between RTS at the same or greater level and RTS at a lesser level by univariate analysis (Table 7). Significant differences were found in the preoperative knee score $(P=0.02)$ and the preoperative Tegner activity scale score $(P<0.01)$. Multivariate logistic regression analysis showed that only the preoperative

Table 4 Comparisons of return to sports activities and impact level between age groups

\begin{tabular}{|c|c|c|c|c|}
\hline & $\begin{array}{l}\text { Overall } \\
(n=74)\end{array}$ & $\begin{array}{l}<70 \text { years } \\
(n=36)\end{array}$ & $\begin{array}{l}\geq 70 \text { years } \\
(n=38)\end{array}$ & ${ }^{*} P$ value \\
\hline Preop. total participation in sports, $n$ (\%) & $59(79.7)$ & $25(69.4)$ & $34(89.5)$ & 0.10 \\
\hline RTS & $55(93.2)$ & $24(96.0)$ & $31(91.2)$ & 0.32 \\
\hline Postop. new participation in sports, $n$ & 7 & 5 & 2 & \\
\hline Postop. total participation in sports, $n$ & 62 & 29 & 33 & \\
\hline Preop. impact level, n High & 12 & 11 & 1 & \\
\hline Intermediate & 5 & 2 & 3 & \\
\hline Low & 42 & 12 & 30 & $<0.01$ \\
\hline Postop. impact level, $n$ high & 7 & 6 & 1 & \\
\hline Intermediate & 2 & 1 & 1 & \\
\hline Low & 53 & 22 & 31 & 0.18 \\
\hline
\end{tabular}

${ }^{*}<70$ years $v s \geq 70$ years

$R T S$ return to sports 
Table 5 Comparison of level in return to sports between the age groups

\begin{tabular}{|c|c|c|c|c|c|}
\hline & & Overall & $<70$ years & $\geq 70$ years & ${ }^{*} P$ value \\
\hline RTS, $n$ (\%) Higher level & & $1(1.8)$ & $0(0)$ & $1(3.2)$ & \\
\hline Same level & & 39 (70.9) & $16(66.7)$ & $23(74.2)$ & \\
\hline Lower level & & $15(27.3)$ & $8(33.3)$ & $7(22.6)$ & 0.40 \\
\hline \multirow[t]{2}{*}{ Tegner activity scale, mean \pm SD } & Preop & $3.1 \pm 1.8$ & $4.0 \pm 1.9$ & $2.9 \pm 1.1$ & $<0.01$ \\
\hline & Postop & $2.8 \pm 1.5$ & $3.3 \pm 1.4$ & $2.7 \pm 1.2$ & 0.16 \\
\hline
\end{tabular}

${ }^{*}<70$ years vs. $\geq 70$ years

RTS return to sports

Table 6 Comparisons of outcomes between osteoarthritis and osteonecrosis

\begin{tabular}{|c|c|c|c|c|}
\hline & & $\begin{array}{l}O A \\
(n=42)\end{array}$ & $\begin{array}{l}\text { ON } \\
(n=32)\end{array}$ & ${ }^{*} P$ value \\
\hline \multicolumn{2}{|l|}{ Age } & $68.7 \pm 8.0$ & $67.7 \pm 8.1$ & 0.81 \\
\hline \multirow[t]{2}{*}{ Knee score } & Preop & $57.1 \pm 12.8$ & $57.5 \pm 15.5$ & 0.72 \\
\hline & Postop & $83.9 \pm 10.1$ & $83.8 \pm 10.5$ & 0.86 \\
\hline \multirow[t]{2}{*}{ Function score } & Preop & $67.6 \pm 12.0$ & $63.4 \pm 9.5$ & 0.15 \\
\hline & Postop & $86.5 \pm 13.0$ & $89.4 \pm 11.3$ & 0.08 \\
\hline \multirow[t]{2}{*}{ sFTA } & Preop & $181.8 \pm 2.5$ & $180.1 \pm 2.0$ & 0.24 \\
\hline & Postop & $170.9 \pm 3.1$ & $172.0 \pm 2.6$ & 0.55 \\
\hline \multirow[t]{2}{*}{$\% \mathrm{MAD}$} & Preop & $18.9 \pm 11.5$ & $24.8 \pm 11.4$ & 0.89 \\
\hline & Postop & $64.8 \pm 10.7$ & $63.3 \pm 11.1$ & 0.62 \\
\hline \multirow[t]{2}{*}{ Tegner activity scale } & Preop & $3.1 \pm 1.9$ & $3.0 \pm 1.8$ & 0.54 \\
\hline & Postop & $2.7 \pm 1.5$ & $2.6 \pm 1.6$ & 0.88 \\
\hline \multicolumn{2}{|c|}{$\begin{array}{l}\text { Preop. total participation in sports, } \\
n(\%)\end{array}$} & $32(76.2)$ & $27(84.4)$ & 0.39 \\
\hline \multicolumn{2}{|c|}{ RTS, $n(\%)$} & $29(90.6)$ & $26(96.3)$ & 0.21 \\
\hline \multirow{3}{*}{$\begin{array}{l}\text { Preop. impact } \\
\text { level, } n\end{array}$} & High & 7 & 5 & \\
\hline & Intermediate & 4 & 1 & \\
\hline & Low & 21 & 21 & 0.91 \\
\hline \multirow{3}{*}{$\begin{array}{l}\text { Postop. impact } \\
\text { level, } n\end{array}$} & High & 4 & 3 & \\
\hline & Intermediate & 2 & 0 & \\
\hline & Low & 29 & 24 & 0.8 \\
\hline
\end{tabular}

OA osteoarthritis, ON osteonecrosis, sFTA standing femorotibial angle, MAD mechanical axis deviation, RTS return to sports

The values are given as mean \pm standard deviation

Tegner activity scale score was related to RTS at the same or greater level, but age, sex, and BMI were not related (Table 8).

\section{Discussion}

The most important finding of the present study was that $91 \%$ of patients aged $\geq 70$ years returned to sports activities, and $77 \%$ of them could perform postoperatively at the same or higher level compared to the preoperative level. These results were not significantly different from the younger age group. However, the ratio of high-impact sports participants was significantly lower in the age $\geq 70$ years group than in the age $<70$ years group. Factors related to RTS at the same or higher level were the preoperative knee score and the preoperative Tegner activity scale.

In general, 'elderly' is defined as a chronological age of 65 or more; however, there is considerable heterogeneity in current orthopedic research [11]. Age is an issue of debate as factor affecting clinical outcomes in HTO, and surgical indication of HTO is often limited to under 70 years $[5,7,12]$. Several studies focused the clinical outcomes in patients aged 70 years and older $[3,13]$. Therefore, the present study referred to patients aged 70 years and older as 'elderly.'

Recent studies have focused on RTS after HTO. A systematic review and meta-analysis of 33 studies involving 1914 patients with a mean age of $50.3 \pm 9.9$ years showed that the rate of RTS after OWHTO was $75.7 \%$ (range 55-100\%) [14]. Another study investigating subjects with a mean age of 50 years demonstrated that the strongest prognostic factor for RTS was continued sports participation in the year before surgery (odds ratio 2.81 ; 95\% CI 1.37-5.76) [12]. A high RTS rate after OWHTO has been reported in the relatively younger generation, and few reports have examined in detail the RTS rates in elderly persons. The present study showed that majority of patients aged 70 years and older participated in low-impact sports with high RTS rate, and age, sex, BMI, and knee alignment did not affect RTS rates.

One of the factors related to RTS in elderly persons is thought to be the extent of surgical invasion and recovery time. Improvements of surgical techniques and fixation devices in OWHTO have enabled early recovery with full-weight bearing, accelerated postoperative rehabilitation, and minimized muscle weakness $[15,16]$. Early bone healing with a stimulatory device may also accelerate the weight bearing activities [17]. Accelerated rehabilitation protocols for OWHTO were introduced and lead to earlier improvement of the clinical results $[15,18]$. In elderly patients, recent accelerated postoperative rehabilitation 
Table 7 Univariate analysis of factors related to the RTS level

\begin{tabular}{|c|c|c|c|c|c|}
\hline Factors & & $\begin{array}{l}\text { Same or greater level } \\
(n=41)\end{array}$ & $\begin{array}{l}\text { Lesser level } \\
(n=14)\end{array}$ & $95 \% \mathrm{Cl}$ & $P$ value \\
\hline Age (years) & & $70.3 \pm 6.9$ & $68.1 \pm 8.0$ & -0.012 to 0.014 & 0.89 \\
\hline Gender (male, \%) & & 22 & 35.7 & -0.311 to 0.091 & 0.27 \\
\hline Body mass index $\left(\mathrm{kg} / \mathrm{m}^{2}\right)$ & & $24.7 \pm 3.4$ & $24.8 \pm 3.2$ & -0.017 to 0.028 & 0.63 \\
\hline Size of medial opening gap ( $\mathrm{mm}$ ) & & $12.2 \pm 2.4$ & $13.3 \pm 3.3$ & -0.071 to 0.019 & 0.26 \\
\hline \multirow[t]{2}{*}{ sFTA (degrees) } & Preop & $180.1 \pm 2.3$ & $181.1 \pm 2.6$ & -0.049 to 0.036 & 0.75 \\
\hline & Postop & $171.3 \pm 2.7$ & $171.2 \pm 2.5$ & -0.031 to 0.034 & 0.92 \\
\hline \multirow[t]{2}{*}{ Knee score } & Preop & $55.7 \pm 11.6$ & $63.1 \pm 10.7$ & -0.017 to -0.002 & 0.02 \\
\hline & Postop & $85.7 \pm 9.5$ & $82.5 \pm 9.7$ & -0.012 to 0.017 & 0.72 \\
\hline \multirow[t]{2}{*}{ Function score } & Preop & $65.3 \pm 12.0$ & $64.4 \pm 10.4$ & -0.003 to 0.012 & 0.23 \\
\hline & Postop & $90.1 \pm 9.7$ & $85.8 \pm 16.0$ & -0.009 to 0.014 & 0.66 \\
\hline Preop. Tegner activity scale & & $3.5 \pm 1.7$ & $3.9 \pm 1.4$ & -0.375 to -0.194 & $<0.01$ \\
\hline
\end{tabular}

The values are given as mean \pm standard deviation

Table 8 Multivariate logistic regression analysis of factors related to RTS at the same or greater level

\begin{tabular}{llll}
\hline Factors & $\mathbf{9 5 \%} \mathrm{Cl}$ & $\boldsymbol{P}$ value & Odds ratio \\
\hline Age (years) & 0.915 to 1.077 & 0.93 & 0.996 \\
Gender (male, \%) & 0.255 to 3.906 & 0.92 & 0.934 \\
Body mass index $\left(\mathrm{kg} / \mathrm{m}^{2}\right)$ & 0.820 to 1.126 & 0.60 & 0.960 \\
Preop. sFTA (degrees) & 0.722 to 1.156 & 0.32 & 0.891 \\
Preop. knee score & 0.941 to 1.038 & 0.32 & 0.976 \\
Preop. Tegner activity scale & 0.439 to 1.032 & 0.04 & 0.663
\end{tabular}

programs seems to work in favor of preventing muscle weakness and increasing RTS.

Types of sports seem to differ among age groups and may affect RTS after HTO. Younger people have a demand for returning to relatively higher impact sports, such as running, baseball, and tennis, whereas older people have a demand for lower impact sports, such as walking, gymnastic training, and golf. The present study demonstrated a higher rate of low-impact sports participants in the age $\geq 70$ years group. Although the return to high -impact sports after OWHTO was high in the younger population [9], most patients return to sports activities with a trend toward performing lower-impact sports [19]. Thus, one of the reasons for the high rate of RTS in elderly persons may be the high rate of preoperative participation in low-impact sports. In addition, since the preoperative Tegner activity scale score in the age $\geq 70$ years group was relatively low, it may not be affected by HTO surgery, and it is easy for the patients to return to the same level postoperatively.

Arthroplasty is an alternative treatment option for knee $\mathrm{OA}$ in elderly patients. The indication for unicompartmental knee arthroplasty (UKA) is similar to that for HTO, and a high RTS rate of $75-100 \%$ has been reported [20-22]. These rates are almost equivalent to the return rate in the present study. A recent systematic review indicated that UKA performed better than OWHTO in patients older than 50 years of age with compartmental knee OA secondary to frontal axis leg deformities [23]. However, there has been controversy over the studies of RTS directly comparing HTO and UKA. Jacquet et al. demonstrated quicker RTS with a higher rate of patients able to practice impact activity and better sports-related functional scores in HTO compared to UKA [24]. In contrast, Kim et al. reported that UKA had better short-term functional outcomes and return to recreational and sports activities than did HTO in patients with medial OA [20]. A systematic review and meta-analysis regarding RTS in elderly patients after UKA showed that higher return rates were observed for lowimpact sports, whereas high-impact sports prevented a full return to activities [25]. Since there are risks of femoral component loosening and polyethylene wear in UKA [26-28], RTS after both surgical procedures needs to be assessed by long-term follow-up.

This study has several limitations. First, there were many cases that were lost to follow-up. More than half of the patients were excluded from this study, which may have caused selection bias. Second, the follow-up period was short. It is unclear whether patients who return to sports after surgery maintain sports activities at the same level for a long time. Third, this study was a retrospective investigation.

\section{Conclusions}

The rate of RTS after OWHTO was high in patients aged 70 years and older with low-impact level. OWHTO is a preferred surgical option for elderly patients who desire RTS. 


\section{Abbreviations}

OA: Osteoarthritis; ADL: Activities of daily living; OWHTO: Opening wedge high tibial osteotomy; RTS: Return to sports; KSS: Knee Society Score; FTA: Femorotibial angle; \%MAD: Percentage of mechanical axis deviation; UKA: Unicompartmental knee arthroplasty.

\section{Acknowledgements}

Not applicable.

\section{Authors' contributions}

Study design was carried out by $\mathrm{AO}$ and KK. Study conduct was done by $A O, K K, S Y, S N, T F, K M$, and YI. Data collection was done by AO, KK, SY, and SN. Data interpretation was carried out by AO, KK, SY, SN, TF, KM, and YI. Drafting manuscript was done by $\mathrm{AO}$ and $\mathrm{KK}$. KK takes responsibility for the integrity of the data analysis. All authors have read and approved the manuscript.

\section{Funding}

No funding was received for this study.

\section{Availability of data and materials}

The data and materials used and/or analyzed during the current study are not publicly available but available from the corresponding author on reasonable request.

\section{Declarations}

\section{Ethics approval and consent to participate}

This study was approved by the ethics committee at Yokohama City University Hospital (\#B190900037).

\section{Consent for publication}

Written informed consent was obtained from all participants.

\section{Competing interests}

The authors declare that they have no competing interests.

Received: 5 August 2021 Accepted: 13 September 2021

Published online: 28 September 2021

\section{References}

1. Coventry MB, Ilstrup DM, Wallrichs SL. Proximal tibial osteotomy. A critical long-term study of eighty-seven cases. J Bone Joint Surg Am. 1993;75:196-201.

2. Koshino T, Yoshida T, Ara Y, Saito I, Saito T. Fifteen to twenty-eight years' follow-up results of high tibial valgus osteotomy for osteoarthritic knee. Knee. 2004;11:439-44.

3. Saito T, Kumagai K, Akamatsu Y, Kobayashi H, Kusayama Y. Five- to ten-year outcome following medial opening-wedge high tibial osteotomy with rigid plate fixation in combination with an artificial bone substitute. Bone Joint J. 2014;96:339-44

4. Gougoulias N, Khanna A, Maffulli N. Sports activities after lower limb osteotomy. Br Med Bull. 2009;91:111-21.

5. Bastard C, Mirouse G, Potage D, Silbert H, Roubineau F, Hernigou P, et al. Return to sports and quality of life after high tibial osteotomy in patients under 60 years of age. Orthop Traumatol Surg Res. 2017:103:1189-91.

6. Faschingbauer M, Nelitz M, Urlaub S, Reichel H, Dornacher D. Return to work and sporting activities after high tibial osteotomy. Int Orthop. 2015;39:1527-34.

7. Liu JN, Agarwalla A, Garcia GH, Christian DR, Redondo ML, Yanke AB, et al. Return to sport following isolated opening wedge high tibial osteotomy. Knee. 2019;26:1306-12.

8. Iseki Y, Takahashi T, Takeda H, Tsuboi I, Imai H, Mashima N, et al. Defining the load bearing axis of the lower extremity obtained from anterior-posterior digital radiographs of the whole limb in stance. Osteoarthritis Cartilage. 2009;17:586-91.

9. Kanto R, Nakayama H, Iseki T, Onishi S, Ukon R, Kanto M, et al. Return to sports rate after opening wedge high tibial osteotomy in athletes. Knee Surg Sports Traumatol Arthrosc. 2021;29:381-8.
10. Tegner Y, Lysholm J. Rating systems in the evaluation of knee ligament injuries. Clin Orthop Relat Res. 1985;198:43-9.

11. Sabharwal S, Wilson H, Reilly P, Gupte CM. Heterogeneity of the definition of elderly age in current orthopaedic research. Springerplus. 2015;4:516.

12. Hoorntje A, Kuijer P, van Ginneken BT, Koenraadt KLM, van Geenen RCl, Kerkhoffs $\mathrm{G}$, et al. Prognostic factors for return to sport after high tibial osteotomy: a directed acyclic graph approach. Am J Sports Med. 2019;47:1854-62

13. Ventura A, Legnani C, Borgo E. Unicompartmental knee replacement in patients aged 70 years and older. Muscles Ligaments Tendons J. 2017;7:611-4.

14. Kunze KN, Beletsky A, Hannon CP, LaPrade RF, Yanke AB, Cole BJ, et al. Return to work and sport after proximal tibial osteotomy and the effects of opening versus closing wedge techniques on adverse outcomes: a systematic review and meta-analysis. Am J Sports Med. 2020;48:2295-304.

15. Schroter $S$, Ateschrang A, Lowe W, Nakayama H, Stockle U, Ihle C. Early full weight-bearing versus 6-week partial weight-bearing after open wedge high tibial osteotomy leads to earlier improvement of the clinical results: a prospective, randomised evaluation. Knee Surg Sports Traumatol Arthrosc. 2017;25:325-32

16. Takeuchi R, Ishikawa H, Aratake M, Bito H, Saito I, Kumagai K, et al. Medial opening wedge high tibial osteotomy with early full weight bearing. Arthroscopy. 2009;25:46-53.

17. Caliogna L, Medetti M, Bina V, Brancato AM, Castelli A, Jannelli E, et al. Pulsed electromagnetic fields in bone healing: molecular pathways and clinical applications. Int J Mol Sci. 2021;22:7403.

18. Morris J, Grant A, Kulkarni R, Doma K, Harris A, Hazratwala K. Early results of medial opening wedge high tibial osteotomy using an intraosseous implant with accelerated rehabilitation. Eur J Orthop Surg Traumatol. 2019;29:147-56

19. Hoorntje A, Witjes S, Kuijer P, Koenraadt KLM, van Geenen RCI, Daams JG, et al. High rates of return to sports activities and work after osteotomies around the knee: a systematic review and meta-analysis. Sports Med. 2017:47:2219-44.

20. Kim MS, Koh IJ, Sohn S, Jeong JH, In Y. Unicompartmental knee arthroplasty is superior to high tibial osteotomy in post-operative recovery and participation in recreational and sports activities. Int Orthop. 2019;43:2493-501.

21. Naal FD, Fischer M, Preuss A, Goldhahn J, von Knoch F, Preiss S, et al. Return to sports and recreational activity after unicompartmental knee arthroplasty. Am J Sports Med. 2007;35:1688-95.

22. Witjes S, Gouttebarge V, Kuijer PP, van Geenen RC, Poolman RW, Kerkhoffs GM. Return to sports and physical activity after total and unicondylar knee arthroplasty: a systematic review and meta-analysis. Sports Med. 2016;46:269-92

23. Migliorini F, Driessen A, Oliva F, Maffulli GD, Tingart M, Maffulli N. Better outcomes and reduced failures for arthroplasty over osteotomy for advanced compartmental knee osteoarthritis in patients older than 50 years. J Orthop Surg Res. 2020;15:545

24. Jacquet C, Gulagaci F, Schmidt A, Pendse A, Parratte S, Argenson JN, et al. Opening wedge high tibial osteotomy allows better outcomes than unicompartmental knee arthroplasty in patients expecting to return to impact sports. Knee Surg Sports Traumatol Arthrosc. 2020;28:3849-57.

25. Papalia R, Zampogna B, Torre G, Diaz Balzani LA, Vasta S, Papalia G, et al. Return to sport activity in the elderly patients after unicompartmental knee arthroplasty: a systematic review and meta-analysis. J Clin Med. 2020;9:1756.

26. Lo Presti M, Costa GG, Cialdella S, Agro G, Grassi A, Caravelli S, et al. Return to sports after unicompartmental knee arthroplasty: reality or utopia? A 48-month follow-up prospective study. J Knee Surg. 2019;32:186-91.

27. Song SJ, Bae DK, Kim Kl, Park CH. Long-term survival is similar between closed-wedge high tibial osteotomy and unicompartmental knee arthroplasty in patients with similar demographics. Knee Surg Sports Traumatol Arthrosc. 2019;27:1310-9.

28. van der List JP, Zuiderbaan HA, Pearle AD. Why do medial unicompartmental knee arthroplasties fail today? J Arthroplasty. 2016;31:1016-21.

\section{Publisher's Note}

Springer Nature remains neutral with regard to jurisdictional claims in published maps and institutional affiliations. 